\title{
Cutaneous Neoplasms in Renal Transplant Recipients
}

\author{
Leonardo F. Domingues*, Willian N. Alves, Marilda Mazzali.
}

\begin{abstract}
Retrospective study evaluating the incidence of skin cancer in renal transplant patients. Of a total of 2,400 transplanted patients, 85 fulfilled the inclusion criteria of the study, with 352 tumors diagnosed, about 108 months post transplantation. More than half of the patients analyzed had more than one tumor (multiple or recurrent), but there was no difference between the characteristics of patients with single or multiple tumors. In both groups, most tumors affected the head and neck, but in the group with multiple tumors, we observed an increase in lesions in limbs over time. Unlike the general population, where basal cell carcinoma is the most frequent form, among the transplanted patients the most common tumor was squamous cell carcinoma, with different degrees of differentiation.
\end{abstract}

\section{Key words:}

Renal transplant, skin cancer, immunosuppression.

\section{Introduction}

Renal transplant recipients are at increased risk for neoplasms, especially cutaneous $[1,2,3,4]$. Risk factors are: the use of immunosuppressive drugs; Virus infection with oncogenic potential; Sun exposure; Race; Smoking; More advanced age and family history of neoplasia [1-5]. The objective of this study was to determine the incidence of cutaneous neoplasms in renal transplant patients and to identify possible risk factors for their occurrence.

\section{Results and Discussion}

Retrospective study with medical records and the database of the renal transplantation program - HC Unicamp.

Inclusion Criteria: renal transplant recipient alone; Age $\geq 18$ years; Diagnosis of cutaneous neoplasia confirmed by biopsy.

Of a total of 2,400 renal transplant recipients, 85 patients met the inclusion criteria. The majority were male $(n=56$, $65.88 \%$ ), with age at diagnosis of the tumor of $57 \pm 10.25$ years.

Tumors were diagnosed 108.6 months after transplantation, and more than half of the patients $(58.8 \%)$ had multiple tumors or tumor recurrence during follow-up. For analysis, patients were divided into 2 groups, according to the number of tumors (single, $n=35)$ and multiple $(n=$ 50). There were no differences between the groups in relation to gender or age. However, the group with multiple tumors had a later diagnosis (116.3 vs. 74.2 months, $p$ $<0.05)$. Most tumors were located in the head and neck, but in patients with multiple tumors, we observed an increase in tumors in limbs over time $(31 \%$ vs. $17 \%$, multiple vs. single, $p<0.05$ ).

Image 1. Distribution of Tumors

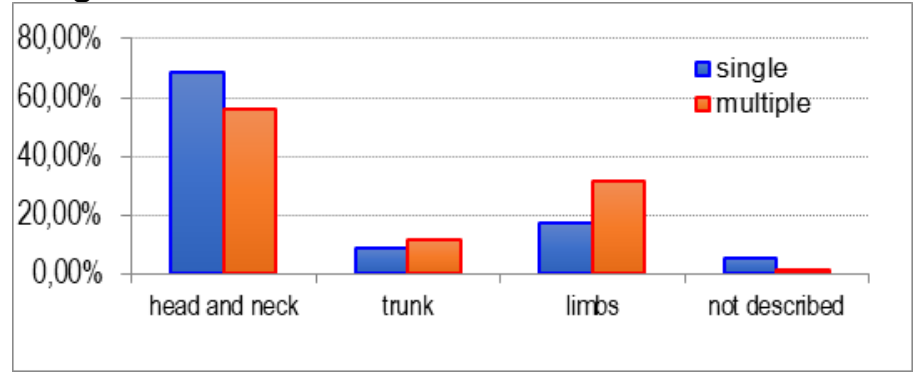

The most frequent histological type in the two groups was squamous cell carcinoma, with different degrees of differentiation.

Image 2. Histological Type of Tumours

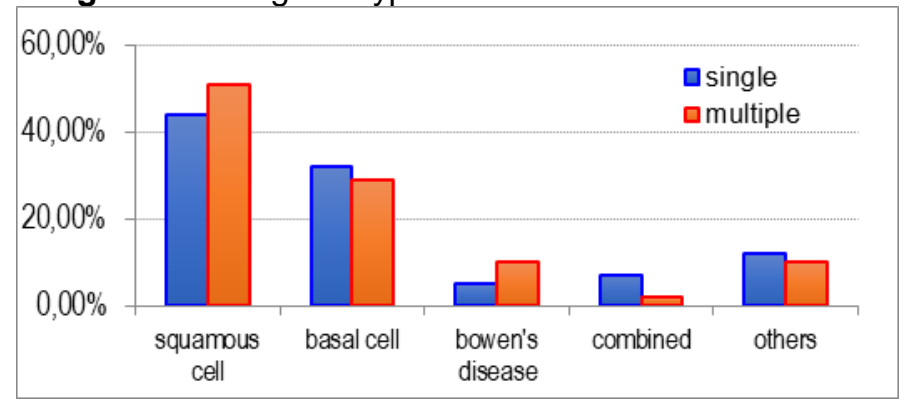

\section{Conclusions}

We observed an increased incidence of squamous cell carcinoma compared to the non-transplanted population. We did not identify risk factors for multiple tumors, but patients with more than one tumor or recurrence had a later diagnosis and a tendency to limb involvement, in addition to head and neck, which was the most frequent site.

\section{Acknowledgement}

Studentship PIBIC-CNPq, 2016-2017.

\footnotetext{
1- Sherston SN, Carrol RP et al. Transplantation 2014; 97:605.

2- Hampton T. JAMA 2005;294:1476.

3- Kessler M, Jay N et al. Transplant Int 2006; 19:908.

4- Ash WA, Bia MJ. Adv Chronic Kidney Dis 2014; 21(1):106.

5- Dantal J, Soulillou JP.N Engl J Med 2005;352:1371.

6- Euvrard S,Kanitakis J.Transplant Oncol 1998; 3:96
} 